\title{
TINTA E PÓ. FOTOGRAFIAS EM VIAGEM
}

DuARTE Belo ${ }^{1}$

Resumo - O trabalho a partir do qual se parte para estas palavras é de natureza fotográfica, num limbo entre o documental e o interpretativo, ou artístico. Essa fronteira pode ser, aliás, muito ténue. No entanto há alguns princípios documentais que se prendem com uma certa ânsia de cobrir um extenso território, todo o espaço português. No registo há duas faces, não podendo deixar de fugir a uma estetização do visível - é um apelo irresistível, talvez um convite ontológico. Este texto é uma reflexão sobre a prática da fotografia de paisagem, território, espaço. Cerca de 30 anos de recolhas fotográficas, mais de 1350000 de imagens feitas, 500000 quilómetros percorridos em território português. Um número crescente de imagens dá origem a um arquivo vasto que se transforma numa entidade viva a partir do qual se estabelecem leituras renovadas, de revisitação, dos lugares fotografados no passado. A complexa teia de relações entre a realidade espacial e a sua representação pela fotografia, procura, mais tarde, formas de materialização do pensamento em diversos suportes, em projetos expositivos e editoriais.

Palavras-chave: Viagem, espaço, fotografia, arquivo.

Abstract - Paint and dust. Travel photographies. The work which lays the ground for these words is photographic in nature, situated between documentary and interpretive or artistic styles. The boundary between these styles can be very tenuous. However, they grow out of documentary principles that stem from an eagerness to cover an extensive territory, namely Portuguese space. This record is double-sided, and it cannot avoid an aestheticization of the visible - an irresistible appeal, which is perhaps an ontological invitation. This text reflects on the practice of landscape photography, depicting territory, space. It represents nearly 30 years of photographic surveys, more than 1.35 million images taken in over 435,000 miles of Portuguese territory. A growing number of images gave rise to a vast archive that has taken on a

1 Duarte Belo (Lisboa, 1968). Formação em arquitetura. Desde 1986 que trabalha no levantamento fotográfico sistemático da paisagem, formas de povoamento e arquiteturas em Portugal. Este trabalho continuado deu origem a um arquivo fotográfico de mais de 1250000 fotografias e vários livros sobre o tempo e a forma do território português. E-mail: dvartebelo@gmail.com 
life of its own, and from which renewed and revisited readings of the places photographed in the past have stemmed. The complex web of relationships between spatial reality and its representation in photography materializes in various media, exhibitions and publishing projects.

Keywords: Travel, space, photography, archive.

Ao fim do dia procuramos um local para a pernoita. Deitamo-nos sobre o solo. A luz é tomada pela noite. Escuridão que se vai revelando num imenso detalhe, que abre novas portas para outras dimensões de tempo e pensamento. Ouvimos o mar, talvez um avião a passar, corre uma brisa suave, temperada. Não tarda a sentir-se a humidade do ar. Nas horas seguintes, se abrirmos os olhos, observamos a rotação da Terra na Via Láctea. A 'abóbada' celeste revela um número ilimitado de pontos luminosos. Estrelas ao redor das quais outros mundos podem existir. Fechamos os olhos. Um universo de lugares em expansão está dentro de nós. Desenhamos viagens imaginárias em distâncias indeterminadas. Percorremos lugares de memórias dispersas. Trazemos um espaço imenso dentro de nós. Como se, de novo, atravessássemos a montanha nevada, a floresta densa, quase impenetrável, ruídos de aves dispersos pelo tempo, o grande rio que transporta enormes penedos polidos, as paisagens cársicas a fazerem lembrar a ossatura de um animal gigante, os mares interiores, a extensa planície, uma última colina para observarmos o oceano, claro, luminoso. Durante o caminho, pontualmente, atravessavamos as cidades, povoadas de faces desconhecidas, de uma cultura dispersa, fragmentada, evolutiva, milenar. Há uma realidade de que nos parecemos aproximar, mas que constantemente nos escapa. Uma intuição. Talvez nada. O Sol nasce. Continuar a caminhar.

Partir para o terreno nunca sabendo o que se vai encontrar, mesmo levando um itinerário previamente traçado, mesmo conhecendo imagens dispersas de várias fontes, mesmo repetindo um percurso que se fizera no passado. Caminhar, fotografar, procurar fixar, de forma progressivamente intensa, aspectos das paisagens e das arquiteturas. A impossibilidade de abarcar um espaço vasto, de o registar exaustivamente pelo nosso movimento, pelas fotografias, transporta-nos para áreas geográficas restritas, espaços cada vez mais reduzidos. De horizontes abrangentes, colhidos, aparentemente, numa única imagem, encontramos pormenores que reafirmam o ilimitado do espaço, a dimensão fratal da realidade. Numa micro-paisagem parece sintetizarmos um espaço mais vasto, reparamos que construímos uma enorme abstração. O mínimo espaço transforma-se em infinito. Há um apelo que nos constrói em lugar novo, que ao mesmo tempo é a fabricação de um objecto, eventualmente singular, desvinculado do seu referente. A navegação por um imaginário complexo, traz outras imagens consigo, elaboradas na mente de cada observador. Livros de fotografias, exposições, imagens num ecrã luminoso, elementos de comunicação estritamente humana, invenções do absurdo, do inatingível ou intangível, do inaca- 
bado permanente. Uma marca deixada na pele, a memória de uma qualquer proximidade e do lugar onde não chegámos. Contraditoriamente, nesses espaços mais pequenos, de imenso detalhe, encontramos o reflexo de nós próprios, que logo se converte em viagem renovada.

À medida que caminhamos e descrevemos a terra pelas fotografias, há uma margem de fazeres, aparentemente informe, que vai ganhando significado. São as pontas de um novelo que nos vai conduzindo por lugares desconhecidos que se bifurcam, ramificam. Parece que nos deslocamos como quem constrói uma fuga, não a fuga de um crime, medo, alguma cobardia, mas a fuga inconformada por uma condição que não se aceita, um movimento para a palavra, a liberdade. Talvez sejam apenas os passos constantemente repetidos na procura do paraíso, de uma terra prometida. Espaço refletido no tempo, lugar de uma pacificação que nunca, sabemo-lo entretanto, nunca vai acontecer. Mas há momentos em que tudo muda. Há pontos de inflexão, caminhos, fotografias, textos, objectos, possibilidade de novos diálogos, uma luz diferente derramada sobre uma mesma paisagem conhecida, agora diferente. Ao mesmo tempo damos um passo evolutivo. O espaço é uma procura constante, como se quiséssemos moldar o nosso corpo a uma realidade que permanentemente muda de forma.

Quando chegamos de viagem olhamos para as fotografias, para o resultado do trabalho. Podemos fazer milhares de imagens, mas deparamo-nos com uma realidade incontornável: o que vimos, a realidade que vivenciámos, era muito mais rica e complexa do que as imagens agora mostram. Mas, nas fotografias de espaço, de um pretenso mundo envolvente, há um fascínio. Não estamos apenas a fotografar os lugares, o território por nós habitado, estamos a registar algo a que já não temos acesso. Fixámos o passado que agora já não volta. As fotografias captam o tempo, talvez mais do que o próprio espaço.

As imagens vão adquirindo, ao longo dos anos, diferentes significados, o que também acontece com o próprio acto de fotografar. Torna-se claro que a tarefa de captura fotográfica do espaço não tem fim, um limite possível, como que explode por sendas antes não imaginadas. As paisagens, o olhar, as tecnologias de registo da realidade, tudo se transforma, sem nunca sabermos, previamente, a sua direção. O desejo de captar o universo visível, as faces da matéria, das coisas e dos seres, desaparece, por fugir a qualquer objetivação, por se esconder quando sobre essa imprecisão repousamos o nosso olhar. Há um diálogo, intrincado e dinâmico, entre espaço, tempo e ser. Entre centenas de milhar de fotografias, vamos alinhavando palavras para tentar descodificar o sentido de todo o caminhar, do que observámos em diferentes tempos agora confluentes no presente. Depois, a sensação de esmagamento, de impossibilidade de processar uma crescente quantidade de informação. Ocasionalmente parece formar-se, vaga, uma ideia coerente, mas que logo se desvanece, antes de a conseguirmos fixar. Aparentemente a compreensão dos nossos próprios fazeres requer uma exteriorização, olhar em redor. No fundo vamos procurando nas margens o sentido, o simbólico do rio que que nos transporta, que tece o pensamento fluido associado aos nossos fazeres. 

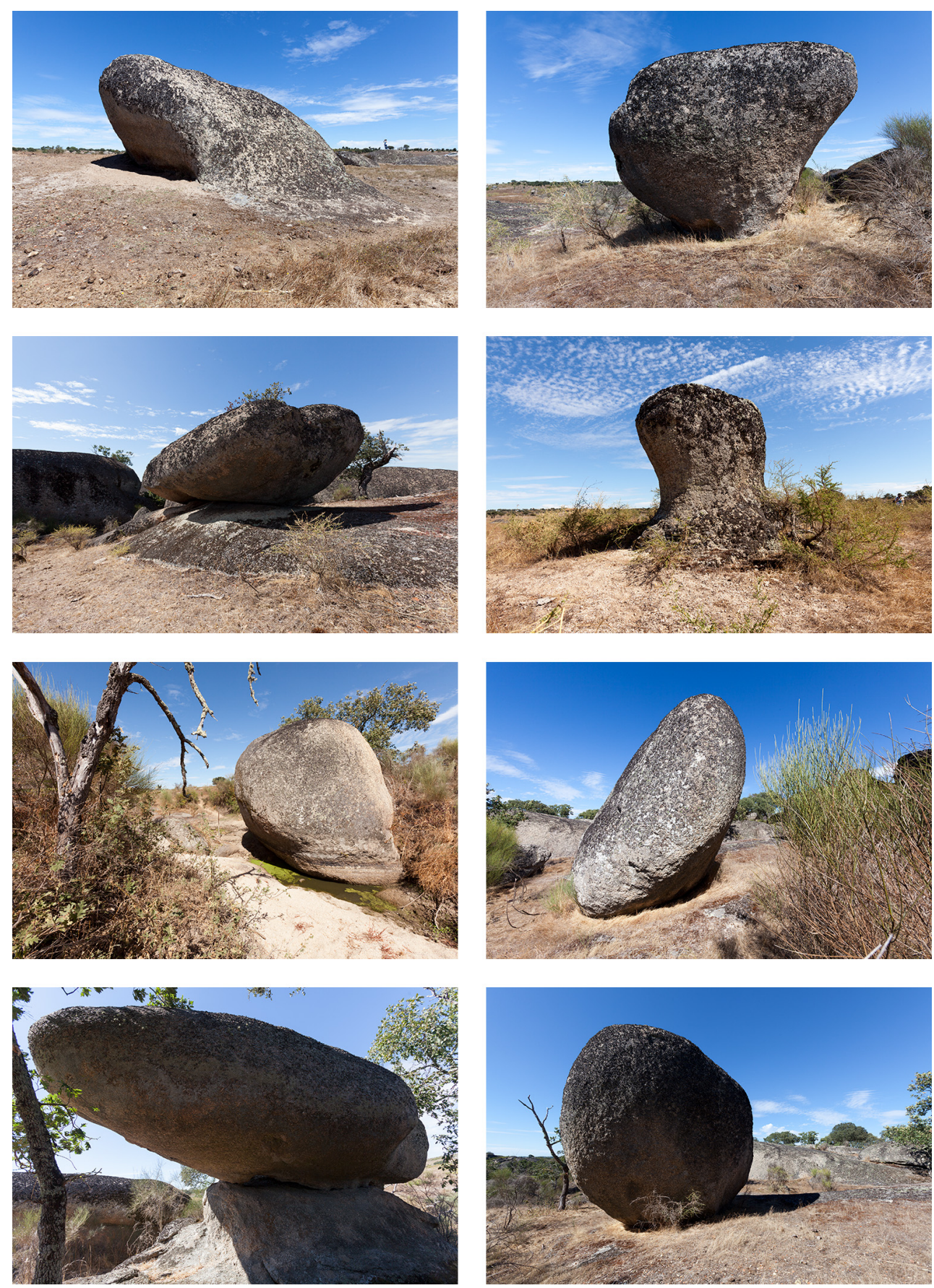

Fig. 1 - Arez (prox.). Nisa, 2014. 

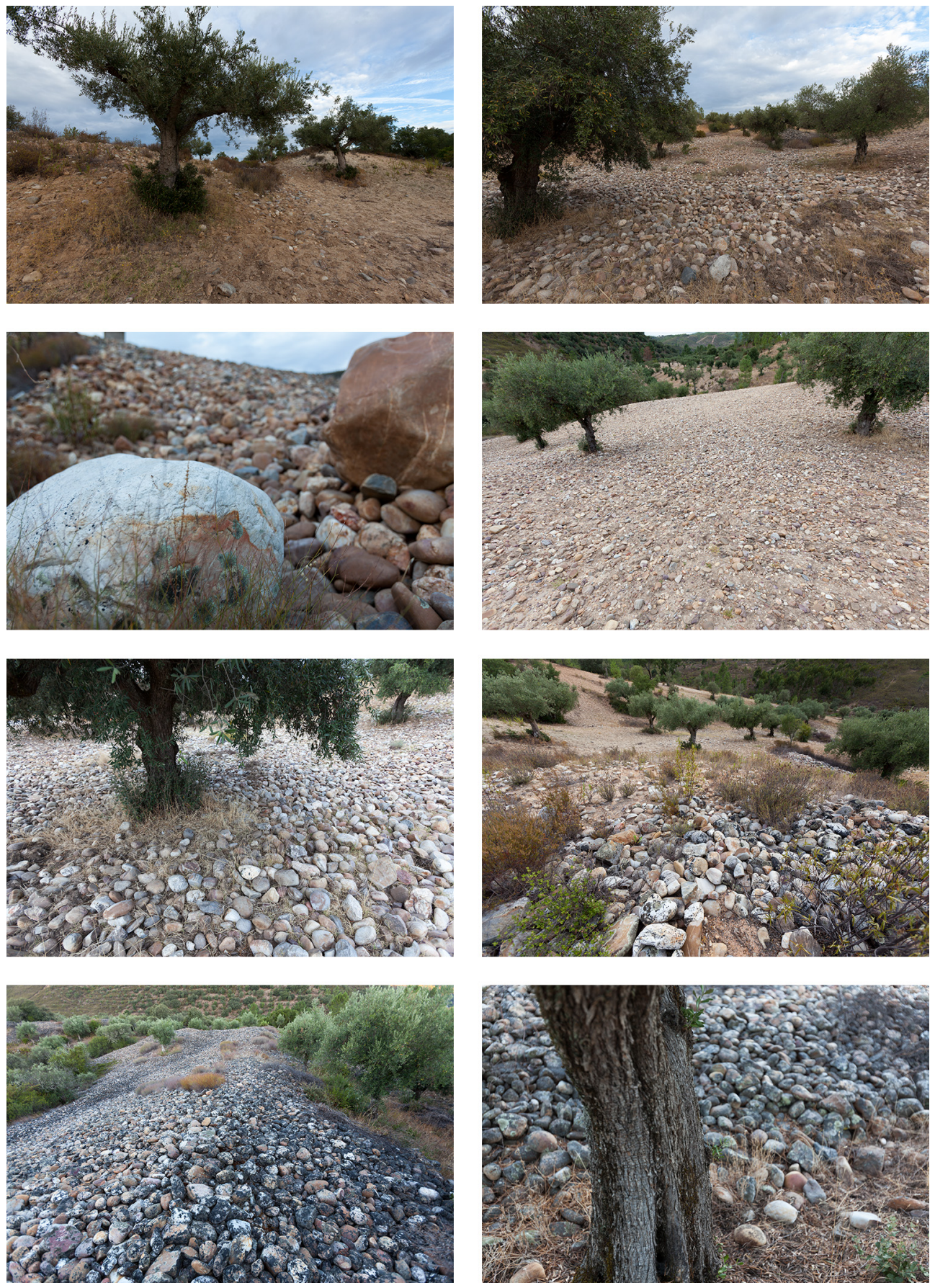

Fig. 2 - Antigas minas de ouro do Conhal do Arneiro. Santana, Nisa, 2014. 

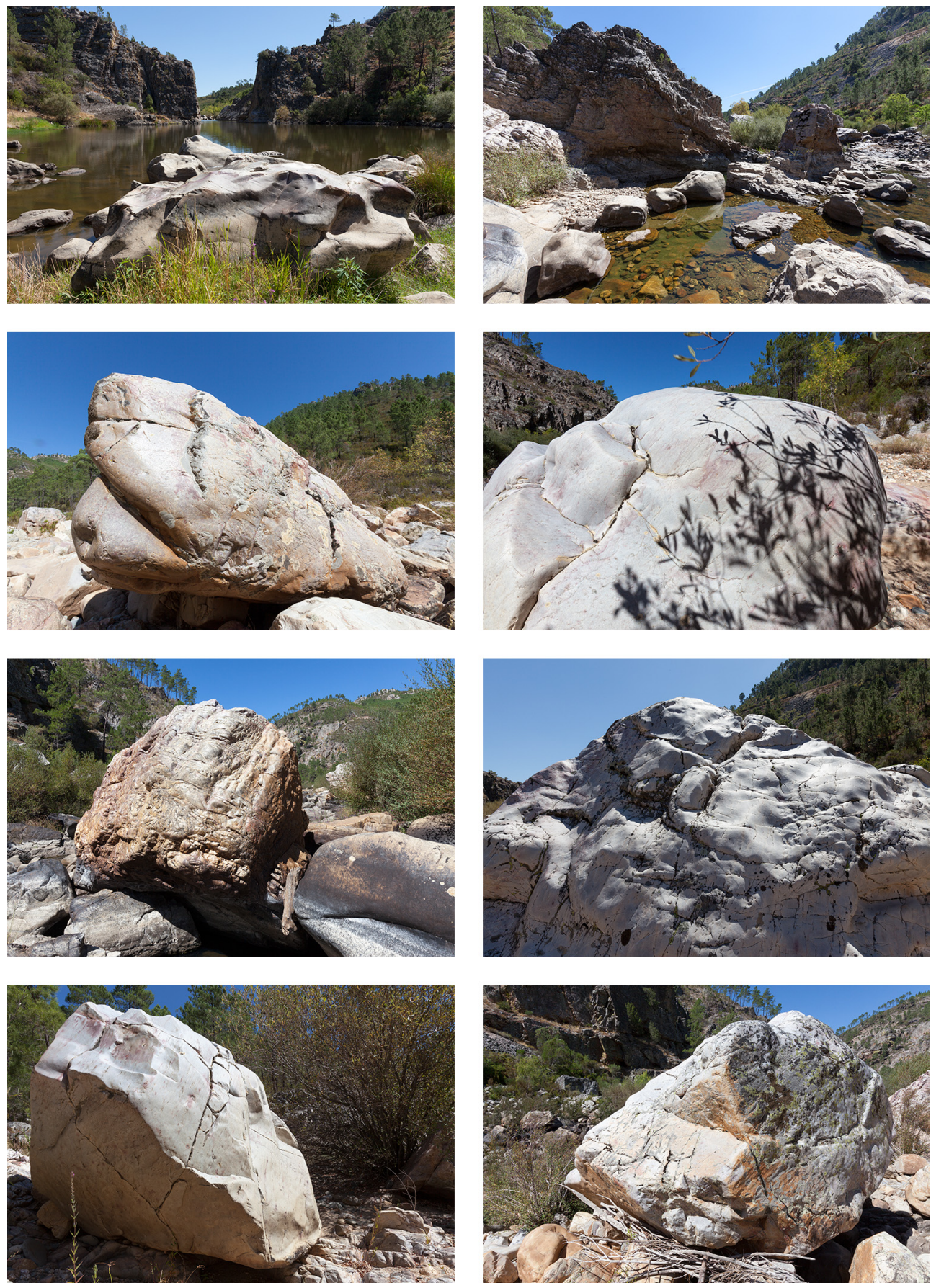

Fig. 3 - Rio Ocreza, Portas de Almourão. Foz do Cobrão. Vila Velha de Ródão, 2014. 

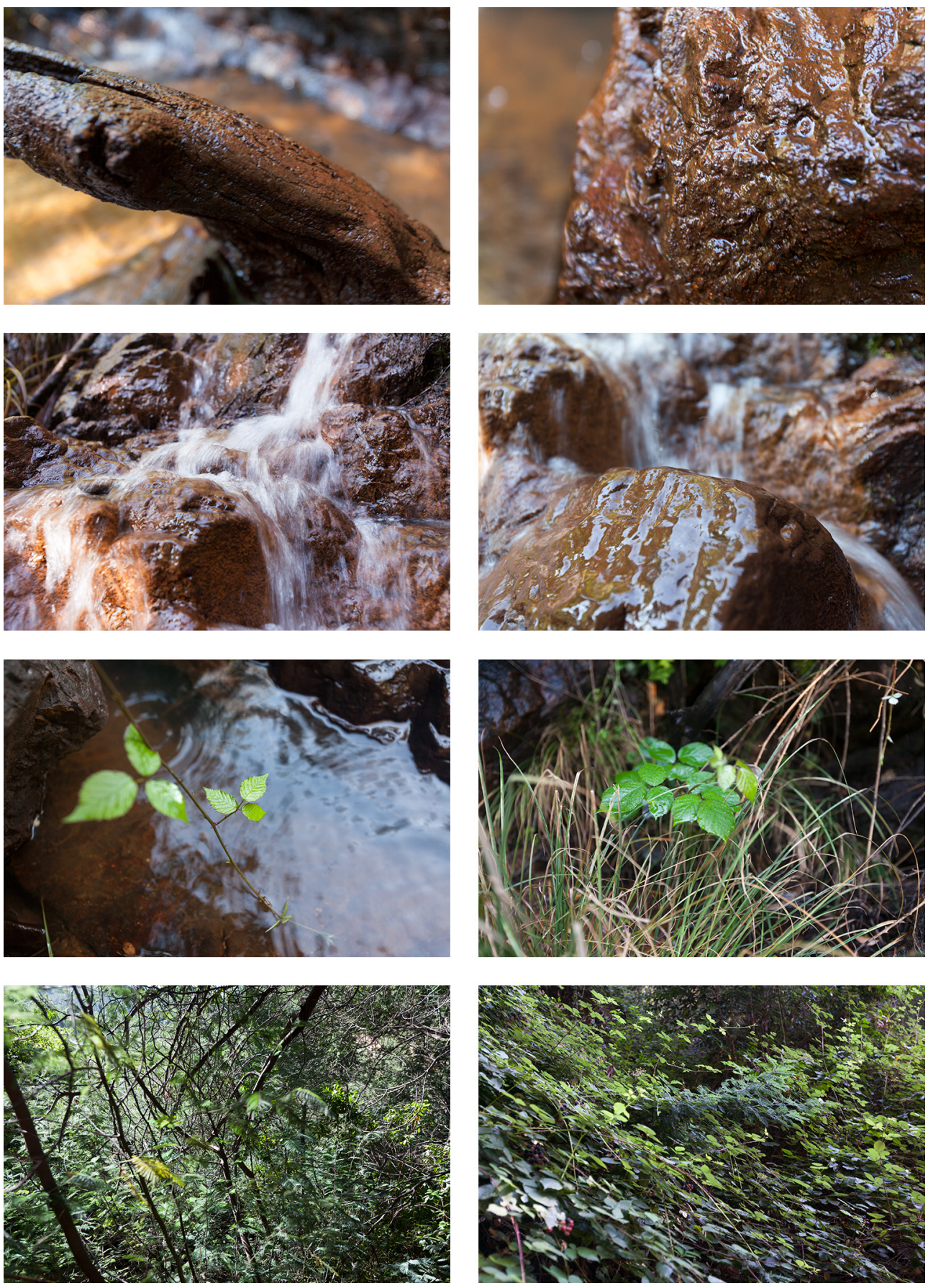

Fig. 4 - Cascatas da Fraga da Água d'Alta. Oleiros, 2014. 

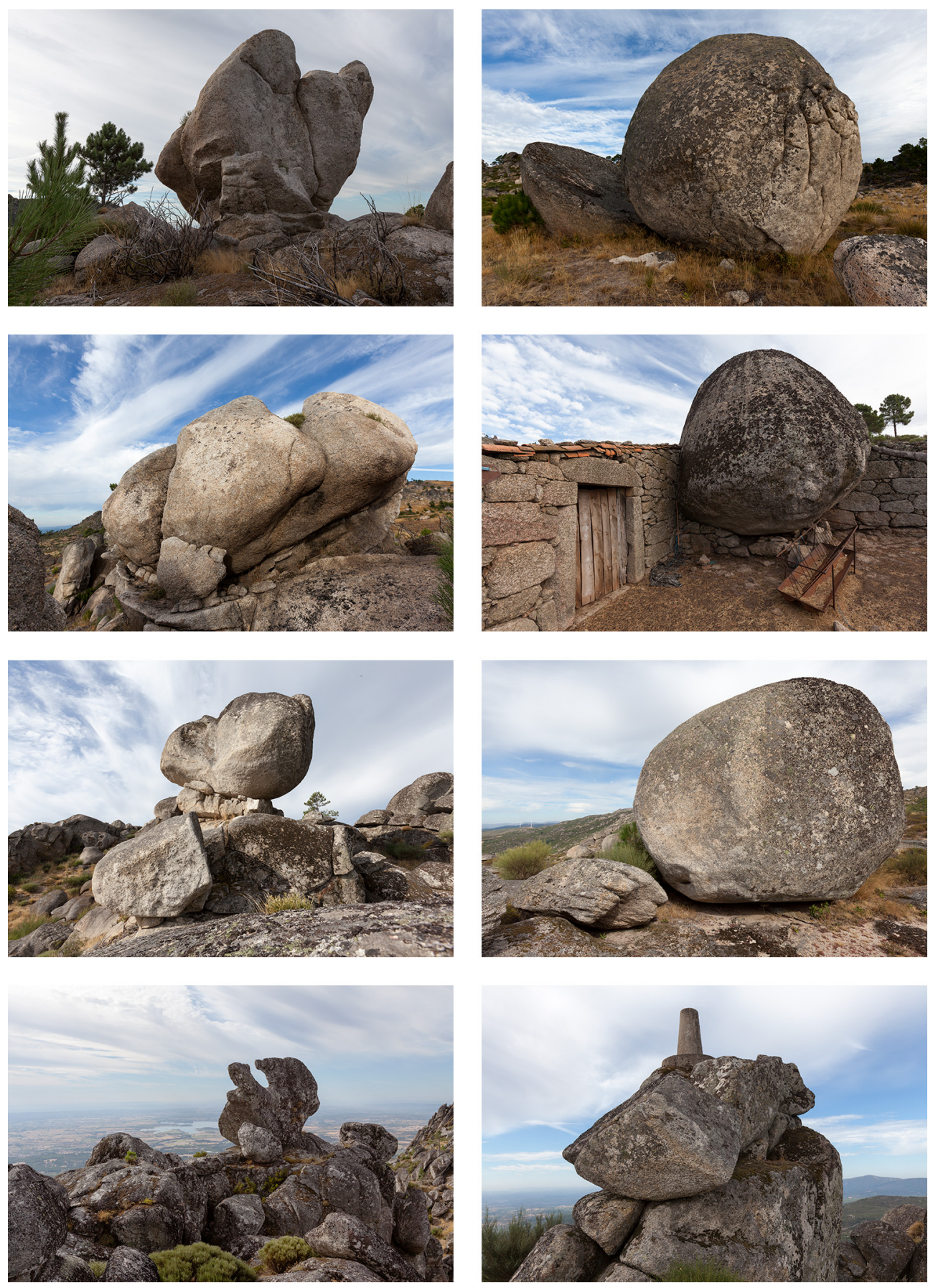

Fig. 5 - Serra da Gardunha. Fundão, 2014. 

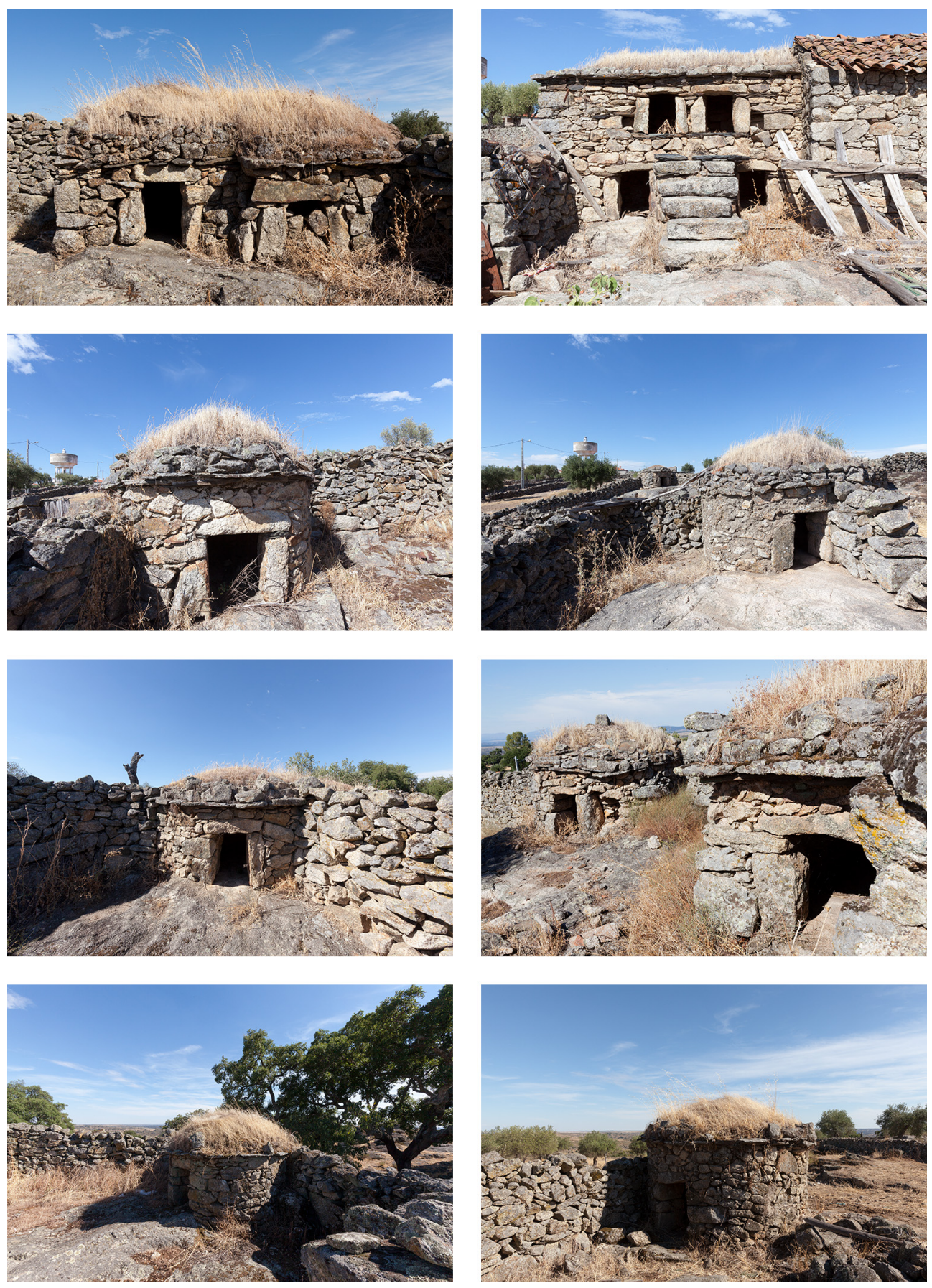

Fig. 6 - Furdas. Salvaterra do Extremo. Idanha-a-Nova, 2014. 

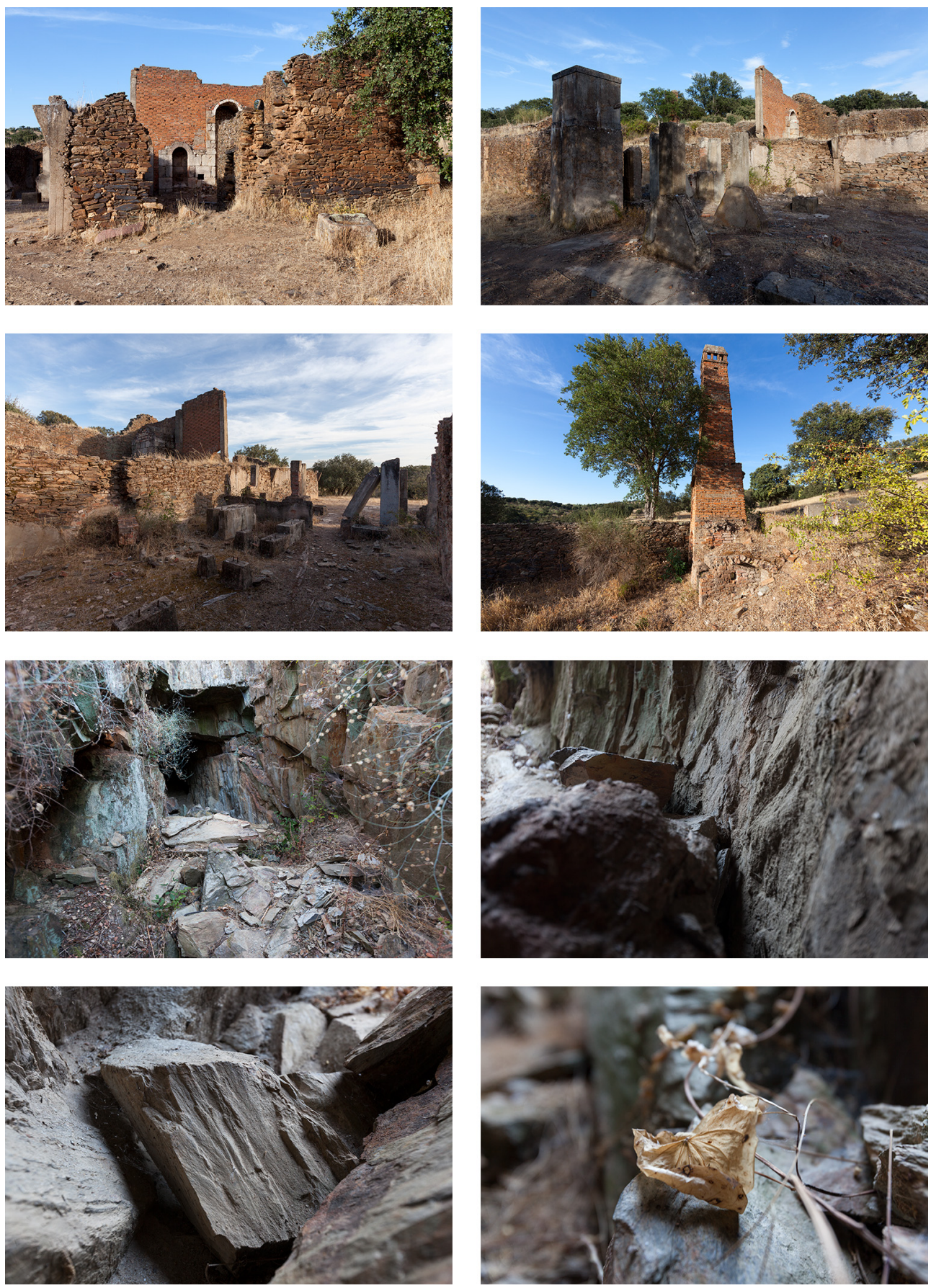

Fig. 7 - Antigas minas. Segura. Idanha-a-Nova, 2014. 

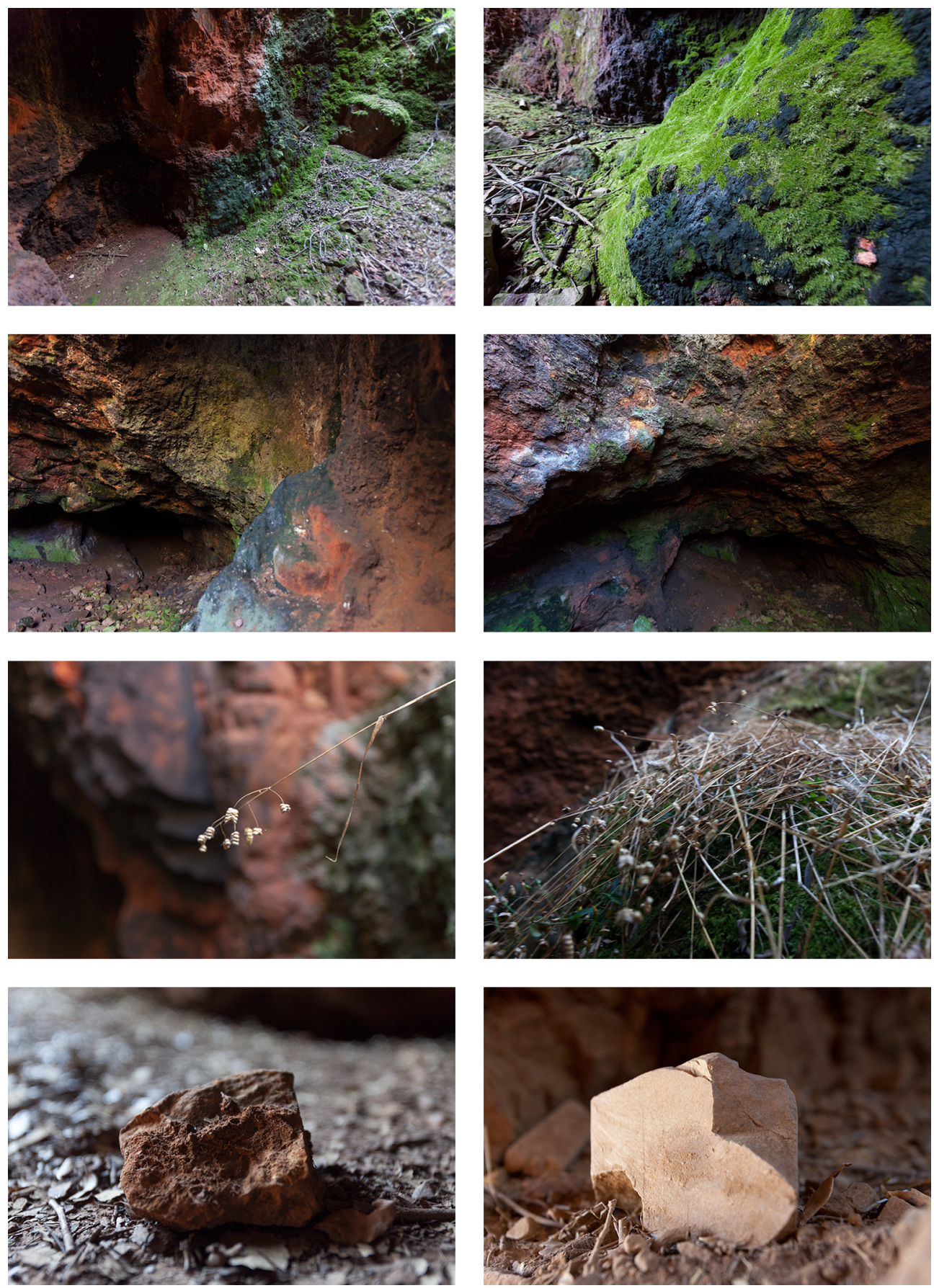

Fig. 8 - Antigas minas da Tinta e do Pó. Monforte da Beira, Castelo Branco, 2014. 

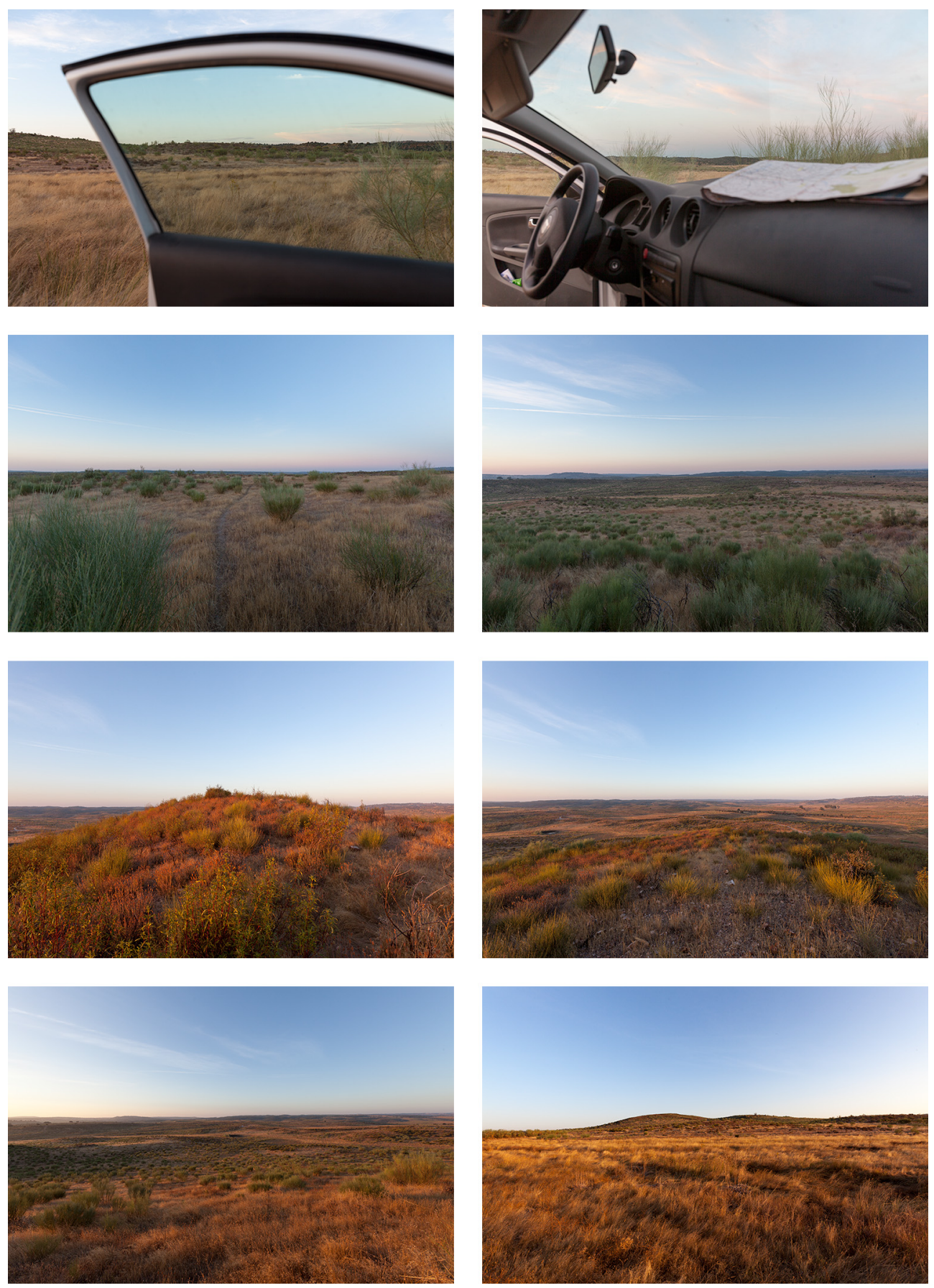

Fig. 9 - Segura (prox.). Idanha-a-Nova, 2014. 
O espaço pode ser uma coerência fictícia plasmada num imaginário de milhares de fotografias. Há uma certa ânsia de comunicar essa construção que se vai fazendo. Há um arquitecto que edifica, que se aproxima de uma síntese de todos os sítios por si visitados, uma casa mínima contendo todos os lugares, um espaço que não é utópico por ser espectral. A pacificação inquieta de lutas arcaicas, talvez inauguradas no misterioso passo lento da consciência de uma espécie que, ao mesmo tempo que rejeitava a imposição de uma natureza hostil, definia o ilimitado, o indeterminado como condição de habitar a terra. Resumir nos passos de uma caminhada milenar, toda a vida de todas as gerações humanas, do passado e do presente, todos os tempos petrificados nas mais arcaicas criaturas, desenhadas nas rochas engolidas pela terra, devolvidas, informes, por vulcões, fogo que tudo apaga. A memória apenas transporta em si, por breves segundos, toda a perplexidade de um espaço que se transforma em tempo. Tempo que não nos vai dizer o que ele próprio é. Não podemos fixar o olhar no rosto de Medeia, sob a condição de ficarmos petrificados. Talvez não possamos encontrar o pensamento sobre a natureza do espaço quando o procuramos frontalmente. Quando procuramos nas margens vamos vislumbrando fragmentos, as peças de um puzzle imenso do qual não sabemos à partida se todas as peças existem, nem tão pouco se o seu desenho fará sentido.

Há, num arquivo extenso, uma vertigem, a sensação de que há algo oculto de que nos vamos aproximando. As fotografias, quando despidas de uma certa plasticidade inebriante, de um belo-fácil, quando se dispõem em conjuntos alargados, estabelecem teias de conexões multiplas com o leitor/observador. Há a consciência progressiva de uma extensão enorme, particularmente quando o arquivo é vivo, quando é regularmente alimentado de novas imagens que, em certa medida, tentam completar lacunas. É o mesmo 'ilimitado' que experienciamos com o movimento sobre a Terra que, em boa verdade, é infinito e indefinido, pois está associado à dimensão tempo, que faz com que os lugares estejam diferentes no segundo momento em que os visitamos. À medida que as recolhas de imagem se vão estendendo a um território mais vasto, maior a sensação do seu sentido de 'sem-limite', como se estivéssemos a desfocar a nossa própria capacidade de compreensão, num movimento, aparentemente, auto-destrutivo, por tender para um aumento exponencial de entropia. Há um limiar difuso entre a lucidez e o colapso, entre o discernimento e o bloqueio, que é tão sedutor, quanto arriscado. Poderá haver um sentido de perda, mas também a noção da dureza e do fascínio da vida, da ausência de consciência numa integração cósmica, fim de algumas das principais angústias humanas, o esplendor da vida em toda a sua ausência de sentido, como que o reflexo absurdo da guerra, da sobrevivência extrema.

Ocasionalmente chegamos a um ponto, breve, em que tudo parece ter significado, todas as fotografias. Há um fascínio pela construção do belo, como se fosse esse um desígnio evolutivo, a procura de uma forma equilibrada, uma grande síntese, de todas as possibilidades. Parece ser este, no entanto, o ponto da perda da consciência, no mergulho na ausência de qualquer verdade, de qualquer juízo sobre as coisas. 
Estamos defronte da barreira da comunicação, um jogo vital em que talvez se jogue a vida e a morte, o diálogo derradeiro antes de enfrentarmos outra qualquer dimensão, talvez apenas mais um passo na construção de um mundo único, que não deixará, em certa medida, de ser apenas nosso. Há aqui um equilíbrio frágil. As fotografias são o diálogo com o mundo visível, com a indefinida teia entre espaço e tempo, pensamento, tinta e pó.

Partia para Arez no dia 28 de agosto de 2014. Aí encontrava colossais penedos de granito, como que as ruínas de uma poderosa civilização perdida. Em vários momentos procurara estes lugares, como se nos pudessem transportar para o sentido corrupto dos tempos presentes. Seguia para Arneiro, para um solo povoado por calhaus rolados de média dimensão, que se estendiam por uma vasta extensão de terreno, até ao Tejo, à primitiva lagoa das Portas de Ródão. Caía a noite entre aquelas oliveiras que agora tomavam a paisagem mineira antiga. Seguimos, na manhã seguinte, para as Portas de Almourão, no rio Ocreza. O leito fluvial exibe, lado a lado, penedos que se soltaram, há não muito tempo, das encostas escarpadas, com outros, cujo polimento revela um tempo longo de exposição às fortes correntes do rio. Depois o miradouro das Corgas, um ponto elevado para a leitura da paisagem. Novamente um rio, uma queda de água, de Água de Alto. Rumamos à serra da Gardunha. Na manhã seguinte percorremos a área do Castelo Velho. Enormes rochedos ciclópicos que se amontuam caoticamente num solo de declives acentuados. Paisagem impressiva onde não nos demoramos para atravessarmos a extensa planície da Beira Baixa. Paramos em Salvaterra do Extremo. As Furdas são a cidade dos porcos. Lugar único e irrepetível. As minas de Segura são um dos últimos pontos de paragem. Noite na paisagem semi-árida daqueles territórios para seguir para Monforte da Beira. A viagem termina nas minas da Tinta e do Pó, como se nesses dois topónimos pudéssemos sintetizar os dias passados, a nossa vida. A ânsia da palavra e do registo, imagens. Tudo o que um dia será pó, átomos, planetas. 